\title{
DIE KRAG VAN SIMBOLE EN RITES IN DIE LITURGIE
}

\author{
C.J.A. $\operatorname{Vos}^{1}$ \\ ABSTRACT \\ THE POWER OF SYMBOLS AND RITES IN THE \\ LITURGY
}

There is an old and dynamic relationship between cult and context. This relationship implies that worship is not experienced in a void. A contextual approach must take into consideration the rise and fall of post-modern saints, where the power of symbols can also be seen. This article considers liturgy as a creative process. The liturgical meaning of symbols are also investigated. There is a specific focus on the symbolism of the Holy Communion. The focus also falls on the Kyrie, the Gloria and the Agnus Dei. Reformed liturgy has placed the Kyrie and the Gloria amongst confessions and mercy declarations. The Kyrie and the Gloria are entwined, and this can be seen in the invocation of commiseration that flows out into the praise of the commiseration. This article states the case for the use of Kyrie, the Gloria and the Agnus Dei during Holy Communion.

\section{PROBLEEMSTELLING}

Die probleem wat in die artikel ondersoek word, is na die plek en funksies van ritus in die liturgie. Met die oog daarop om die probleemondersoek relevant te maak, word aangedui dat die ondersoek 'n kontekstuele invalshoek het.

Die ondersoek spits hom toe op die Kyrie eleison, die Gloria en die Agnus Dei. Die vraag wat in die ondersoek gevra en beantwoord word, is: Watter liturgiese plek en funksies het die Kyrie eleison, die Gloria en die Agnus Dei?

1 Prof. C.J.A. Vos, Dekaan, Fakulteit Teologie, Universiteit van Pretoria, Pretoria 0002. E-pos: cjavos@postino.up.ac.za 


\section{2. 'N INVALSHOEK}

Dit is Maandagmôre. Kollegas ontmoet mekaar by die werk. "Hoe was die naweek?" 'n Uitwisseling oor die weer, uitstappies, 'n besoek aan die teater en sportverslae. Behoort kerkbesoek en die ervaring van die erediens tot die naweek se belewenisse? Op 'n manier. Wat wel duidelik is, is dat die belangstelling in religieuse simbole en rites groei (vgl. Stark 2003:92). Die vraag is egter watter waardering mense heg aan simbole en rituele handelinge in die erediens. Die simbole wat onder die soeklig kom, is die nagmaalsimbole brood en wyn. Die rituele handelinge wat ter sprake is, is die Kyrie eleison, die Gloria en die Agnus Dei.

Die fokus val in die volgende paragraaf op die kontekstuele aspek van die liturgie.

\section{3. 'N KONTEKSTUELE INVALSHOEK}

Daar bestaan 'n ou en dinamiese relasie tussen kultus en konteks (Barnard 2000:5). Onder "kultus" word die erediens as ruimte van ontmoeting met die lewende God en mense, en ook die ontmoeting tussen mense, verstaan. Die "konteks" is die ruimte waarbinne mense elke dag leef, werk, speel en droom. Hierdie relasie tussen kultus en konteks bring mee dat die erediens nie in 'n leë ruimte geskep en ervaar word nie. Die erediensganger leef in 'n bepaalde tyd, sosiale en kulturele en konteks. Hierop moet die liturg in sy/haar liturgie altyd ag gee.

'n Kontekstuele invalshoek moet ook rekening hou met die opkoms (en ondergaan!) van postmoderne heiliges, en hand aan hand daarmee, rituele en simbole in die Westerse kultuur. Marcel Barnard (2001: 209-230) wys in 'n boeiende artikel op prinses Diana aan wie die rol van 'n postmoderne heilige toegeken is. By die hekke van Kensington Palace, die blyplek van die prinses, is bloeiende blomme neergelê, langs die rouroete het honderde duisende mense gestaan, en is publiek gerou. Uit liturgiese oogpunt was nie net die hierdie spontane, min of meer religieuse, rituele uitbarsting boeiend nie, maar ook die uitvaart. Hierdie liturgie was 'n mengsel van die liturgie van die Church of England, 'n poplied van Elton John (oorspronklik geskryf vir die sekssimbool Marilyn Monroe) en 'n toespraak van die oorledene se broer. Verskil- 
lende betekenissisteme, Christelike liturgie, popmusiek en familie, is vermeng tot 'n nuwe sisteem (Barnard 2001:211).

'n Tweede voorbeeld van die krag van simbole kom in J.J.R. Tolkien se boek, The Lord of the Rings, aan die lig. Hieroor het Danie du Toit (2003:27) insiggewend geskryf. Die hooftema in The Lord of the Rings is mag en magsmisbruik en die voortdurende versoeking om aan die verleiding van mag toe te gee.

Die ring word self 'n simbool van mag, en die begeerte om die ring te besit, verteenwoordig 'n sug na mag en die wil om beheer te kry. En daarmee saam kom die vernietigende effek van mag en die onwilligheid van die maghebber om dit prys te gee. In die verhaal is daar ook ander ringe ter sprake wat mag gee, maar die ring waarom dit eintlik gaan, verteenwoordig algehele mag. Dit is dié ring wat al die ander ringe beheer soos die inskripsie daarop aandui:

One ring to rule them all, one ring to find them. One ring to bring them all and in the darkness bind them.

Dié ring het die vermoë om die draer daarvan te verlei en magsdronk te maak. Slegs die wysste mense is bereid om die mag (die ring) prys te gee. Wanneer die wyse Gandalf byvoorbeeld weier om die ring in besit te neem, praat hy van "a power too great and terrible" en sê hy: "the wish to yield to it would be too great for my strength."

In die verhaal word dit aan Frodo, een van die "klein mensies", 'n bobbit, oorgelaat om die gevaarlike tog aan te pak en die ring na Mount Doom te neem - die enigste plek waar dit vernietig kan word. Dat Frodo die ring kan dra sonder om daardeur gekorrupteer te word, hang saam met sy eiesoortige onskuld.

The Lord of the Rings kan natuurlik onafhanklik van enige Christelike interpretasie verstaan word en dit hoef nie deur 'n Christelike bril gelees te word nie. Dit bly 'n fantasiewerk ryk aan simbole. Tog is dit duidelik dat Tolkien in sy skepping van die fantasiewêreld geïnspireer is deur die Christelike boodskap en die waardes waarmee hy vertroud was. Die krag van die ring as simbool kom in die verhaal op 'n meesleurende wyse aan die lig. Mense van ons dag wat die boek lees en die rolprent-trilogie gesien het, is bewus van die krag van simbole. Daarom moet liturge die krag en werking van simbole in die liturgie saam met die erediensgangers ontdek en met mekaar deel. 
Ritusse is sekere (gewoonte-)handelinge waaraan mens vashou. Die koskultuur en kleremodes is twee voorbeelde hiervan. Wie jonk en in pas met die gees van die tyd is, eet pizzas en pastas en soms ook McDonald's, en dra Calvin Klein-jeans.

'n Kontekstuele liturgie vra na 'n kreatiewe liturgie. Dit kom van die volgende paragraaf aan die bod.

\section{LITURGIE AS KREATIEWE PROSES}

Die Ou en Nuwe Testament bied nie 'n vaste vorm waarin die liturgie deur die eeue gegiet kan word nie (Vos 1997:29). In die lewende Christelike tradisie wat onder andere uit die oerbronne van die Ou en Nuwe Testament en die latere kerklike tradisies leef (Barnard 1985: 66-383; Strydom 1994:9-144; Schuman 1998:26-36), is daar sekere patrone, kleure en klanke wat waargeneem kan word. Maar in elke tyd moet die oerbronne en kerklike tradisies nuut en opnuut geïnterpreteer word sonder om ontrou te wees aan die tradisies waarbinne 'n bepaalde liturgie leef.

Hier volg 'n gedig wat impulse gee vir nadenke oor 'n kreatiewe liturgie.

Glasblaser

Sy gees sweef soos in die oerverhaal oor donker leegtes broei chaos.

Hy stook in sy vuurryp oond gesmelte glas versigtig en breekbaar.

Deur sy pyp blaas hy haar vol lewe, suig elke lugborrel dan weer sekuur uit.

Sy oë keur haar gloeiende rondings;

haar hete lyf koel hy sissend af, laaf haar in pienk poeier.

Hy klink haar sonder kraak

La Rochére, 1475

Met die eerste oog opslag is dit glashelder dat hierdie gedig oor ' $\mathrm{n}$ glasblaser wat 'n vaas kunstig gemaak het, handel. Dit is ook moontlik om in die gedig die skepping van die aarde te sien. Dit gaan dus oor die skeppingsproses. Hierdie raakpunt met die liturgie maak dit moontlik om in die lig van die gedig oor die liturgie as skeppingsproses na te dink. 
Die liturg maak die liturgie versigtig en breekbaar. Al is die liturgie vooraf gemaak, kan dit nogtans in die hitte van die oomblik, as die lewende gemeente saamkom, in skerwe breek. Die waarmerk van die liturgie, deur 'n liturg gemaak, bied geen waarborg dat dit verwondering in die erediens gaan wek nie.

Dit is die liturg se werk om die liturgie vol lewe te blaas. Die liturgie moet sodanig wees dat dit as 'n lewende liturgie deur die gemeente ervaar word. Daarom moet die liturg "elke lugborrel" wat die liturgie se skoonheid bederf, "sekuur uitsuig". Die liturg moet die gloeiende bewegings van die liturgiese handelinge met fyn oë goedkeur, en die liturgie ook vir die gemeente en God mooi maak. Die ontwerp van 'n liturgie behoort iets van 'n kunswerk te vertoon. Dit is 'n skeppingsproses. In die erediens, anders as met die maak van 'n vaas, klink die liturg en die gemeente deur die liturgie 'n glasie op God se heil. Want in die liturgie word God se heil gevier. Die heil word veral ook deur simbole en ritusse gevier.

In die vervolg van die artikel is die aandag gerig op die Kyrie eleison, die Gloria en die Agnus Dei as ritusse.

\section{SIMBOOL EN RITE}

Marcel Barnard (2003) omskryf liturgie breedweg "as a science of Christian rites and symbols". Die ganse liturgie is met simbole en rites deursuur. In die simbool en rites kom die spiritualiteit van die liturgie na vore. 'n Spiritualiteit van die liturgie beoog om die lewe van die gelowige in 'n outentieke belewing van die liturgie te wortel sodat die hele lewe ' $n$ in praktykbring van die Paasmisterie is (Polfliet 2003: 164). Liturgiese spiritualiteit neem die viering van die liturgie as bron (Polfliet 2003:168).

\subsection{Die liturgiese sin van simbole}

'n "Simbool" is 'n teken met 'n meerwaarde en oop vir verskillende betekenisse. Daarom staan dit teenoor 'n wetenskaplike term. In die wetenskap is "lig" vas te stel as 'n elektromagnetiese straling met 'n golflengte van ongeveer 400 tot 780 millimikron. In die simboliek, byvoorbeeld, in die liturgie, is dit egter ' $n$ veelkantige begrip. Dit dui byvoorbeeld die Godheid aan, sowel as sy helende en vernietigende 
krag (Joh. 1:9 en 3:19). Kerse en fakkels kan sowel 'n teken van hoop en verbondenheid, as ook van afweer en beswering van die kwade wees (Barnard 2001:215-216).

Drie dimensies bepaal hierdie simboliese meerwaarde (Post 2001: 34). Ten eerste veronderstel 'n simbool deelneming. Die word "simbool" is afgelei van die Griekse $\sigma v \mu \beta a ́ d \lambda \epsilon \iota \nu$ wat "versamel", "uitwissel” (oorganklik) en "mekaar ontmoet" (wederkerig) beteken. In die Griekse Oudheid dui 'n $\sigma u ́ \mu \beta o \lambda o v$ 'n potskerf aan wat in twee gebreek is. Twee bondgenote ruil dan die stukke uit as bewys van hulle onderlinge ooreenkoms. Een stuk het op sigself geen betekenis nie (Depoortere 1994:374). Die besitter van een helfte kon in die toekoms aan 'n ander party sy deel aanbied as bewys van 'n ooreenkoms, mits dit presies in die ander deel pas (Trias 1998:103, 106 e.v., 109). Sodoende word die ooreenkoms (h)erken. Die saamvoeg van twee helftes klink ook deur in een van die weinige Bybeltekste waar die begrip "simbool" voorkom, naamlik in die Kersverhaal van Lukas (Luk. 2:19). Daar staan dat Maria na 'n aantal verwarrende ervaringe en ontmoetinge "alles wat gesê is, onthou en telkens weer by haarself daaroor nagedink het" ( $\sigma v \mu \beta a ́ \lambda \lambda o v \sigma \alpha)$. Sy stem in met alles wat daar oor die Kind gesê word en vind vrede in haar hart.

In die tweede plek word die simbool in 'n groot mate bepaal deur konvensies en kodes (Vos 2002:85). Op grond van konvensies in die Christelike geloofsgemeenskap het brood en wyn die betekenis van nagmaalsimbole verkry. In die verband het kultuurbepaalde kodes 'n belangrike rol gespeel. Dit is die bewuste, maar meer dikwels die onbewuste konteks wat die verwysende tekenfunksie van simbole bepaal (Post 2001:35).

Die derde kenmerk wat 'n teken tot simbool maak, is ikonisiteit. 'n Simbool bestaan uit hoofde van 'n ooreenkoms tussen dit wat in die verwysing teenwoordig of opgeroep word en dit wat daar vervolgens gebeur, tot by die tekensimbool toe (Post 2001:35). Die maaltyd was vir die eerste gemeente 'n primêre simbool. As die belangrikste voedingsmiddel van alle kultuurvolke is brood dienooreenkomstig 'n simbool van voeding. Aangesien brood mense voed, voed dit ook die gemeenskap tussen hulle (Heinz-Mohr 1998:58e.v.). Wyn speel beide as landbouproduk en genotmiddel 'n sentrale rol in Palestina (Heinz-Mohr 
1998:330). In die tekens as simbole is die bekende reeds teenwoordig: daar bestaan 'n sekere ooreenkoms tussen beide.

Die krag van simbole lê op verskillende vlakke. Hierdie krag bestaan onder meer in die onthulling van meervoudige betekenis waaruit verbeelding groei (Ricoeur 1987:249; vgl. ook Vos 1996:34-37). 'n Egte simbool is altyd meerduidig (Depoortere 1994:375) of meersinnig (Lukken 1999:20). Simbolisering is 'n uitgaan na 'n onbekende landskap (Barnard 2000:7). 'n Simbool soos doop en nagmaal is 'n direkte, nie-rasionele kommunikasie met 'n ander werklikheid (Vos 1996: 56-59; Uytenbogaardt 1998:371). Daar word 'n verband gelê tussen ons menslike werklikheid en die ander, Gods werklikheid. Simbole voer mense mee na 'n werklikheid agter die simbool (Houtepen 1997:32). Deur simbole word 'n beweging per visibilia ad invisibilia voltrek, van die uiterlike, simboliese teken na die innerlike onsigbare geloofswerklikheid (Polfliet 2003:170).

\subsection{Simbole in die liturgie}

As liturgiese simbooltekens speel wyn en brood die rol van 'n onthulling van meervoudige betekenis. Buitendien stel dit mense in staat om die ander werklikheid, naamlik die van God se heil, deelagtig te word. Die aardse werklikheid — brood en wyn — verteenwoordig in die nagmaal geestelike werklikhede.

As nagmaalsimbool verwys die brood na die voedsel wat Christus bring deurdat Hy sy liggaam laat breek het. Deur hierdie daad is dit ook 'n simbool van gemeenskap met Christus en met mekaar. Deur die brood van die lewe ontvang ons God se heil.

Die wyn verwys as nagmaalsimbool na die bloed van Christus, wat met die oog op die heil van mense gestort is. Brood en wyn verseker ons van die realiteit wat die ware vlees en bloed van Christus vir ons inhou. Met hierdie realiteit het ons gemeenskap. Hierdie twee simbole vervul die funksie van verbintenis en interaksie. Brood en wyn verenig die gelowige met die Een waarna dit verwys. Hierdie verbintenis bewerk interaksie tussen die gelowige en Christus. Die interaksie is 'n geloofsdaad.

Die liturgiese simbole, brood en wyn, deel die heil mee wat Christus skenk. In die brood en die wyn sien ons wat God se liefde sy Seun gekos het. Brood uit die grafoond en wyn uit die groot Boland. Die 
brood en die wyn maak die heil sigbaar, tasbaar en proebaar. In die brood proe ons en in die wyn ruik ons die ene liefde. Ook proe ons in die brood die opstanding en die ewige lewe. Die wyn laat ons die vreugde oor ons bevryding smaak (Vos 2002:86).

\subsection{Rites in die liturgie}

Die simbole waarna in die voorafgaande deel verwys is, moet deur rites gedra word. In die gedig Ritueel word verklaar:

Ik houd het kleine ritueel in ere, opdat je elk moment terug kan keren.

Rites weef'n patroon waarvolgens die simbole se skoonheid, waarde en betekenis na vore kom. In die Weste is daar 'n betreurenswaardige neiging om die liturgie te verintellektualiseer. Die klem op die kategetiese of didaktiese bedoeling is goed, maar dit mag nie die "misterie van Christus" waarom dit in die liturgie handel, in die weg staan nie (Chauvet 2003:78). Kreatiwiteit in die liturgie mag nie allereers op die vlak van die uitwerking van nuwe tekste of die uitvinding van nuwe simboliese handelinge plaasvind nie, maar dit moet om die "egtheid" van die verskillende rituele handelinge gaan (Chauvet 2003: 78). Dit alles vra liturgiese beplanning, styl en kommunikasie.

\subsubsection{Die Kyrie eleison, die Gloria en die Agnus Dei}

Die vraag wat hier in die brandpunt staan, is die na die betekenis en funksie van die Kyrie eleison, die Gloria en die Agnus Dei in die liturgie.

Ontstaangeskiedenis is verstaansgeskiedenis (Heitink 1993). Gevolglik is dit verstandig om die historiese dimensie van die Kyrie eleison na te speur. Die Kyrie eleison het in die Vroeë Kerk as klaagsang inslag gevind. Dit is nie as skuldbelydenis bedoel nie, maar as huldiging en aanroeping van die helpende Here tot wie 'n mens hom in nood kan wend (Albrecht 1989:42). Die Kyrie eleison, "Here, ontferm U", is meestal gesing. Dit was 'n antwoord op die voorbede wat deur 'n diaken aangekondig of uitgespreek is. Hiermee het die gemeente hulle instemming betuig. Dié gebruik het al in die vierde eeu in Jerusalem voorgekom. Chrysostomos was ook hiermee bekend. Dit kom verder in die Apostoliese Konstitusies voor. In die Romeinse liturgie van 
Gelasius (Pous van 492-496) word dit ook aangetref. By Gregorius die Grote (ongeveer 540-604) het daar is verandering gekom. Die formule Christe eleison is wel as wisselroep gebruik. Op weeksdae is hierdie bede toegelaat en is die Kyrie eleison en die Christe eleison gesing. Hierdie gebruik het gedurende die sewende en agtste eeu ook na die Sondagse mis oorgegaan. Aan die begin van die negende eeu is die Eleisonuitroepe vervang met die drie keer Kyrie eleison, die drie maal Christe eleison en die drie keer Kyrie eleison-uitroepe (Albrecht 1989:43). Op die lang duur het die uitroep dus heeltemal losgeraak van die gebede en het dit 'n selfstandige liturgiese element geword (Van Rongen 1990:35).

Die Reformasie met sy nadruk op die Skrif het die Kyrie en Gloria aanvanklik wisselend gebruik en later laat verval (Vrijlandt 1989:187). Tot by die Reformasie was die Kyrie 'n koorstuk. Luther het dit in 'n eenvoudige vorm aan die gemeente oorgedra. In die Straatburgse liturgie (1525) is die Kyrie tot 'n wisselsang tussen die koor en die gemeente omskep. Die gemeente het met die Duitse teks ("Herr, erbarme dich - Christ erbarme dich") op die Griekse Teks ("Kyrie eleison - Christe eleison") gereageer (Albrecht 1989:44). Die Kyrie het nie in Calvyn se Straatburgse liturgie van 1538 voorgekom nie. In sy Geneefse liturgie van 1542 het Calvyn die skuldbelydenis van Bucer uit 1537 oorgeneem. 'n Genadeverkondiging ontbreek in die teks. Dit word 'n gebed om vergewing. Die Kyrie en Gloria is opsioneel en verval deurgaans. Dit het te doen met die verset teen die absolusie. Calvyn het dit wel nuttig geag om aan die skuldbelydenis 'n belofte toe te voeg wat die sondaar tot hoop op versoening en vergewing opwek. Eers in die sestigerjare van die vorige eeu het die ekumeniese beweging ruimte vir die Kyrie as lied geskep.

Ten einde die teologiese diepgang van die Kyrie eleison te probeer peil, moet die betekenisskakering daarvan eers in die Psalms en daarna in die Evangelies nagegaan word. Ongeveer twintig keer klink daar in die Psalms op: "Here, ontferm U!", of variante daarvan. By Psalm 51:3 ("Ontferm U oor my, o God/LXX: Eleison me, ho theos!") is die konteks van die uitroep duidelik en konsekwent die van persoonlike skuld (Schuman 2003:191). Hieraan verwant is Psalm 41:5, ook vers 11 (LXX: 40:5 en 11). Maar in die gebed duik tegelyk vanaf vers 6 die tipe vyandigheid op wat in soveel Psalms die bidder beweeg tot die 
uitroep Kyrie, eleison me! (vgl. Ps. 30:11; 41:5 en 11). In die omgewing van die uitroep om ontferming wemel dit van vyande, samesweerders, bedreiging, doodsgevaar en skenders van die Goddelike voorskrifte. In een woord: goddeloses (vgl. Ps. 31:10, 12, 14, 16). In Psalm 123 (vgl. vers 4 en die aansluitende vervolg in Ps. 124) wat deel van die pelgrimspsalms (Ps. 120-134) vorm, is die "ek" wat om ontferming roep die gemeenskap van Israel self:

Ontferm U oor ons, Here, ontferm U oor ons/

Eleison bumas, kyrie, eleison bumas!

Vir die eerste, Joods-Christelike getuies van die verhaal van die gekruisigde Jesus as die verhaal van die Lewende, kon die "ek" van bepaalde Psalms 'n Messiaanse vulling kry (Schuman 2003:193; Braulik 2003). So word Jesus self die een wat met Psalm 30:12 kon sê:

Ek was in rou, maar $\mathrm{U}$ het my van vreugde laat dans .....

Die Jerusalemse kerk het dit agt dae voor Paasfees gevier volgens die oudste leesrooster wat aan ons bekend is, die Armeense Leksionarium (Barnard 1998:200; Schuman 2003:193). Op soortgelyke wyse kon die Evangeliste in die lydensverhaal Psalms in Jesus se mond lê waarin die Kyrie opklink. In dié verband kan mens dink aan Jesus se woord oor die verraad van die man wat saam met Hom die tafel deel of aan sy laaste word aan die kruis: "Vader, in u hande gee Ek my gees oor" (vgl. Luk. 22:21 par. en Ps. 41:10, vergelyk vers 5 en 11; respektiewelik Luk. 23:46 en Ps. 31:6, vergelyk vers 10) (Schuman 2003:194). Hierdie Kyrie-aanroep van die lydende Jesus is ten diepste 'n aanroep en 'n oproep van die Goddelike ontferming van mense in diep nood.

In twee van die drie lofsange wat Lukas in sy proloog oorlewer, kom die tema van die Goddelike ontferming aan die orde (Schuman 2003:188-189). Die twee lofsange is die lofsang van Maria en die lofsang van Sagarias. In Maria se lofsang word in Lukas 1:50 verklaar:

Hy bewys ontferming van geslag tot geslag aan dié wat Hom eer. 
In die slot van Maria se lied kom die Goddelike eleos/misercordia in Lukas 1:54 en 55 weer terug:

Sy dienaar Israel het Hy

te hulp gekom

deur te dink aan sy beloftes

van ontferming

soos Hy dit toegesê het

aan ons voorvaders,

aan Abraham en sy nageslag

tot in ewigheid.

In die lofsang van Sagaria kom die tema twee maal voor. Lukas 1:72-75 sluit inhoudelik direk by die lied van Maria aan:

...om Hom te ontferm

oor ons voorvaders

en sy heilige verbond te onthou.

Met 'n eed het Hy dit bevestig

aan ons voorvader Abraham

dat Hy sou gee dat ons,

gered uit die hand van vyande,

Hom onbevrees kan dien

in vroomheid en opregtheid

al die dae van ons lewe.

Die tweede geval kom in Lukas 1:78 en 79 voor:

Danksy die genadige ontferming

van ons God.

Soos die môreson sal Hy opgaan

en uit die hoogte op ons afstraal,

om lig te bring aan dié

wat in duisternis

en in die skaduwee

van die dood lewe,

om ons voetstappe te rig

op die pad van vrede.

Die Kyrie eleison is in die Evangelies tot Jesus gerig. In Matteus kom daar vyf voorbeelde hiervan voor (Schuman 2003:190-191). In Matteus 9:27 roep twee blindes wat Jesus volg uit: "Ontferm U tog oor ons, Seun van Dawid!"

Net voor die intog in Jerusalem is daar weer twee blindes, nou langs die kant van die pad, wat twee maal roep (Matt. 20:30 e.v.): 
Here, Seun van Dawid, ontferm U tog oor ons!

Hulle volg Jesus ná hulle genesing, met oop oë dus. Tussen hierdie twee genesingsverhale van die blindes, roep eers iemand in belang van haar dogter, en later iemand in belang van sy seun (Matt. 15:22 en 17:14-15):

Ontferm U oor my, Here, Seun van Dawid! My dogter is in die mag van 'n duiwel, en dit gaan sleg.

Here, ontferm $\mathrm{U}$ tog oor my seun, want hy is geestelik versteurd en hy ly verskriklik. Hy val dikwels in die vuur en dikwels in die water.

Dit gaan in die gevalle om siekte en kwale wat mense buite hulle persoonlike skuld vaskluister aan 'n lot wat hulle nie self begeer of gesoek het nie (Schuman 2003:191). Hulle roep Kyrie eleison! gaan om wat in die liturgie as "die nood van die wêreld" bekend staan.

Hierdie Bybelse kontoere werp 'n lig op die liturgiese funksie van die Kyrie, Gloria en Agnus Dei. In die Kyrie moet daar twee liturgiese funksies bewaar word. In die eerste plek gaan dit om die bewussyn van persoonlike skuld. In die tweede plek gaan dit in die Kyrie om die nood van die mensdom. Dit gaan om die mensdom wat onder die las van skuld sug. In die Romeinse Massaal 1970 word die Kyrie met drie bewuste aanroepinge die meeste gebruik (Schuman 2003:196):

Here, ontferm U; Christus, ontferm U; Here, ontferm U!

Meestal word daar ná die Kyrie die Gloria as loflied gesing. Die Gloria is 'n baie ou en eerbiedwaardige lofsang, waarmee die kerk wat in die Heilige Gees vergader, God die Vader en die Lam verheerlik en om ontferming smeek (Heinz 2003:33). Die eie aard van die Gloria kan ook in 'n mosaïek van tekste waarin die Kyrie weer terugkom, in kombinasie met die Agnus Dei aangebied word (Schuman 2003:196). 'n Voorbeeld hiervan is:

Here, eniggebore Seun, Jesus Christus, Here God,

Lam van God, Seun van die Vader,

$\mathrm{U}$ wat die sonde van die wêreld wegneem, ontferm U oor ons!

$\mathrm{U}$ wat die sonde van die wêreld wegneem, aanvaar ons smeekgebed!

$\mathrm{U}$ wat aan die regterhand van die Vader sit, ontferm U oor ons! 
'n Liturgiese voorstel wat die Kyrie, die Gloria en die Agnus Dei in een teks naatloos weef, is die volgende:

Here, ontferm U; Christus, ontferm U; Here, ontferm U.

Ons redding kom van ons God, wat op die troon sit,

en van die Lam!

Amen!

Die lof en die heerlikheid,

die wysheid, die dank en die eer,

die mag en die sterkte

behoort aan ons God

tot in alle ewigheid.

Amen! (Openbaring 7:10, 12).

Die Kyrie eleison kan gesing word. Lied 248 kan vir die doel gebruik word. Die Gloria kan ook by wyse van 'n lied uitgedruk word (Jossutis 1991:234). In dié verband kan aan Lied 180, 223 en 367 gedink word.

In die Gereformeerde liturgie het die Kyrie en die Gloria onder die skuldbelydenis en die genadeverkondiging ingeskuif ('n voorbeeld hiervan is Strydom 1994:299). Die Kyrie en die Gloria is egter onlosmaaklik verweef (Josuttis 1991:234), en wel in die liturgiese gebeure van aanroeping om ontferming wat uitmond in die lof oor die ontferming. Verder kom die Christologie as lyding en verhoging ook liturgies in die spel. Die aangewese plek van die Kyrie, die Gloria en die Agnus Dei is die tafeldiens.

Op hierdie stadium kan die Nagmaal ingestel word.

\section{LITURGIE VIR DIE LEWE}

In hierdie artikel is ' $n$ kontekstuele en kreatiewe liturgie aan die orde gestel. Die liturgiese sin en funksies van simbole en ritusse is ook ondersoek. Daar is in diepte gekyk na die liturgiese betekenis en funksie van die Kyrie, en Gloria en die Agnus Dei. In die gereformeerde liturgie het die Kyrie en die Gloria onder die skuldbelydenis en die genadeverkondiging ingeskuif. In hierdie artikel is gepleit dat die Kyrie, die Gloria en die Agnus Dei ook by die tafeldiens gebruik word.

'n Liturgie waartydens rituele en simbole lewenseg voorkom, is 'n liturgie vir die lewe. 


\section{BIBLIOGRAFIE}

Albrecht C

1989. Einführung in die Liturgik. Göttingen: Vandenhoeck \& Ruprecht.

BARNARD A C

1985. Die erediens. Pretoria: NG Kerkboekhandel.

BARNARD M

1998. De heilige Schrift. In: P. Oskamp \& N.A. Schuman (reds.), De weg van de liturgie. Tradities, achtergronden, praktijk (Zoetermeer: Meinema), pp. 195-209.

2000. Liturgiek als wetenschap van christelijke riten en symbolen. Amsterdam: Universiteit van Amsterdam.

2001. Prinses Diana als postmoderne heilige en een kerkdienst in een museum: Tendensen in de dynamiek van cultus en cultuur vanuit een West-Europees perspectief. Verbum et Ecclesia 22(1):209-230.

2002. Liturgiek als wetenschap van christelijke riten en symbolen. Amsterdam: Vossiuspers AUP.

2003. Kongres oor Psalms en liturgie. 21 Augustus 2003.

\section{BRAULIK G}

2003. Psalms and liturgy: their reception and contextualisation. Verbum et Ecclesia 24(2):309-330.

\section{Chauvet L-M}

2003. Het liturgisch voorgaan in de moderniteit: mogelijke kansen van een crisis. In: Ars celebrandi of de kunst van het waardig vieren van de liturgie (Leuven: Acco), pp. 63-83.

\section{DEPOORTERE K}

1994. Sacramenten vieren (1); Waar het leven icoon wordt. Collationes. Vlaams Tijdschrift voor Theologie en Pastoraal 24(4):363-388.

Du TOIT D R S

2003. Rapport. 21 Desember, p. 27.

\section{HEINZ A}

2003. Overwegingen omtrent de kunst om de kerkelijke liturgie te vieren. In: J. Lamberts (red.), Ars celebrandi of de kunst van het waardig vieren van de liturgie (Leuven: Acco), pp. 17-41.

\section{HEINZ-MOHR G}

1998. Lexikon der Symbole. Bilder und Zeichen der Christlicher Kunst. München: Chr. Kaiser.

\section{Heitink G}

1993. Praktische Theologie. Kampen: Uitgeverij Kok. 


\section{HOUTEPEN A W J}

1997. Vensters op het oneindige. Over God als open vraag aan onze cultuur. In: Th. De Boer, A.W.J. Houtepen \& J.A. Montsma (reds.), God geeft te denken. Bijdragen aan het spreken en denken over God (Zoetermeer: Meinema), pp. 23-38.

\section{JosutTis M}

1991. Der Weg in das Leben. Eine Einführung in den Gottesdienst. München: Chr. Kaiser.

\section{LUKKEN G}

1999. Rituelen in overvloed. Een kritische bezinning op de plaats en de gestalte van het christelijk ritueel in onze cultuur. Baarn: Ten Hare.

\section{POLFLIET J}

2003. Op zoek naar een spiritualiteit van het liturgisch vieren. In: J. Lamberts (red.), Ars celebrandi of de kunst van het waardig vieren van de liturgie (Leuven: Acco), pp. 163-178.

\section{POST P}

2001. Ritualiteit: begrippe en dimensies. In: M. Barnard \& P. Post, Ritueel bestek (Zoetermeer: Meinema), pp. 33-41.

\section{RICOEUR P}

1987. Erzählung, Metapher und Interpretationstheorie. Zeitschrift für Theologie und Kirche 232-253.

\section{SCHUMAN N A}

1998. Vertrekpunte. In: P. Oskamp en N.A. Schuman (reds.), De weg van de liturgie. Tradities, achtergronden, praktijk (Zoetermeer: Meinema), pp. 23-38.

2003. Een schoot van ontferming. Kyrie eleison en de christologische verlegenheid. In: A. Lanser, J. van Nijen, C. Strak \& S. Stoppels (reds.), De kunst van ontfermen. Studies voor Gerben Heitink (Kampen: Uitgeverij Kok), pp. 187-201.

\section{STARK C}

2003. Een interviewserie met bekende Nederlanders over hun beleving van de kerkdienst. In: G. Heitink, H. Stoffels (reds.), Niet zo 'n kerkganger (Kampen: Uitgeverij Kok), pp. 91-111.

\section{STRYDOM W M L}

1994. "Sing nuwe sange, nuntgebore". Liturgie en lied. Bloemfontein: NG Kerkboekhandel.

\section{TRÍAS E}

1998. Thinking, religion. The symbol and the Sacred. In: J. Derrida \& G. Vattimo, (eds.), Religion (Cambridge), pp. 95-110.

\section{UYTENBOGAARDT H}

1998. Symbool en rite. In: P. Oskamp \& N.A. Schuman (reds.), De weg van de liturgie. Tradities, achtergronden, praktijk (Zoetermeer: Meinema), pp. 371-378. 
VAN RONGEN G

1990. Met al de heiligen. Liturgie in hemel en op aarde. Barneveld: Uitgeverij De Vuurboek.

\section{Vos C J A}

1996. Die volheid daarvan. Pretoria: HSRC.

2003. Enkeldiep. Pretoria: HSRC.

2002. Liturgische taal als metaforische taal. In: M. Barnard \& N.A. Schuman (reds.), Nieuwe wegen in de liturgie (Zoetermeer: Meinema), pp. 82-94.

Vos C J A \& Pieterse H J C

1997. Hoe lieflik is u woning. Pretoria: NG Kerkboekhandel.

VRIJLANDT M A

1987. Liturgiek. Delft: Meinema.

$\begin{array}{ll}\text { Trefwoorde } & \text { Keywords } \\ \text { Rites } & \text { Rituals } \\ \text { Simbole } & \text { Symbols } \\ \text { Liturgie } & \text { Liturgy }\end{array}$

